\title{
AUGE Y OCASO DEL CARBÓN MINERAL EN URUGUAY. UN ANÁLISIS HISTÓRICO DESDE FINES DEL SIGLO XIX HASTA LA ACTUALIDAD*
}

RETO BERTONI

Programa de Historia Económica y Social, Facultad de Ciencias Sociales, Universidad de la República, Uruguay ${ }^{a}$

CAROLINA ROMÁN

Instituto de Economía, Facultad de Ciencias Económicas y de Administración, Universidad de la República, Uruguay ${ }^{\mathrm{b}}$

\begin{abstract}
The study of the rise and fall of mineral coal as an energy source can shed light on the characteristics of energy transition in Uruguay. This article presents historical series of coal consumption for Uruguay since the last decades of the $19^{\text {th }}$ century until nowadays (1879-2011). The "coal era" can be placed in the first decades of the $20^{\text {th }}$ century. The use of this mineral in four sectors may explain the dynamic of the coal consumption as a result of different trajectories that characterize the Uruguayan energy transition pattern of stops and goes. In addition, the article put forward three factors to explain the decisions to shift from coal to other energy sources: relative prices and freights, technological innovations and institutional aspects.

* Received 11 January 2013. Accepted 4 October 2013. Versiones anteriores de este documento se presentaron en el Seminario de Investigación del Programa de Historia Económica y Social de la Facultad de Ciencias Sociales de la Universidad de la República. Agradecemos los comentarios recibidos, especialmente por parte de Henry Willebald. También, nuestro agradecimiento a Albert Carreras, Mar Rubio, Xavier Tafunell y César Yáñez por sus contribuciones en la motivación inicial de este trabajo. Finalmente, agradecemos las valiosas sugerencias realizadas por los tres revisores externos, las cuales han contribuido a mejorar este artículo. Los errores remanentes son de nuestra entera responsabilidad.

a Constituyente 1502, $4^{\circ}$ piso, 11200, Montevideo. Teléfono: (00598) 24136400, int.417. Correo-e: reto.bertoni@cienciassociales.edu.uy.

b Joaquín Requena 1375, 11200, Montevideo. Teléfono: (00598) 24001369, int.116. Correo-e: croman@iecon.ccee.edu.uy.
\end{abstract}


Keywords: Coal consumption, Energy transition, Uruguay.

JEL Classification: N76, Q43.

\section{RESUMEN}

El análisis del auge y ocaso del carbón mineral como fuente energética en Uruguay aporta información para entender las características de la transición al petróleo. Este trabajo presenta una serie de consumo de carbón mineral en Uruguay desde fines del siglo XIX hasta la actualidad (1879-2011). La «era del carbón» se ubica en las primeras décadas del siglo XX. La demanda efectiva de cuatro sectores contribuye a explicar el comportamiento del carbón como el resultado de diferentes trayectorias que caracterizan el patrón uruguayo de retrocesos y recuperación. Además, se discuten tres factores explicativos precios y fletes, innovaciones tecnológicas y aspectos institucionales- que están detrás de las razones que impulsaron a los actores estratégicos a adoptar fuentes energéticas modernas.

Palabras clave: Consumo de carbón, Transición energética, Uruguay.

\section{INTRODUCCIÓN}

Los procesos de transición energética contribuyen a comprender aristas relevantes del desarrollo económico y social, dado que permiten incorporar al análisis histórico información sobre la dinámica del cambio en las fuentes de energía, el origen de la misma y su uso.

El estudio de las transiciones energéticas en Uruguay no tiene una gran tradición en la producción historiográfica y, por lo tanto, es importante destacar el carácter pionero -aunque inconcluso-del trabajo Energía y política en el Uruguay del siglo XX, de Labraga et al. (1991), cuyo único tomo se subtituló «Del carbón al petróleo», centrado en el período 1900-1930.

Existen estudios referidos a períodos específicos de la historia energética del país ${ }^{1}$ y algún diagnóstico sobre la evolución de la matriz energética en las últimas décadas ${ }^{2}$, pero la dinámica de la transición energética en el largo plazo y su relación con el desarrollo solo han sido objeto de estudio en los últimos años a partir de los esfuerzos realizados en el seno de la Historia Económica ${ }^{3}$. En otras investigaciones, el objeto fue la transición de las energías orgánicas a

\footnotetext{
1 Por ejemplo, Oxman (1961) y Jacob (1979).

2 Como Méndez Galain (2008) y Bertoni et al. (2011).

3 Cf. Bertoni (2002 y 2011); Bertoni y Román (2006 y 2008); Bertoni et al. (2009).
} 
las fósiles, mientras que el presente artículo se focaliza en el comportamiento del consumo de carbón como insumo para la producción de otras formas de energía y en su utilización como energía final por algunas actividades económicas; así como en los factores explicativos de las decisiones sobre las fuentes energéticas que hay que utilizar.

El primer paso para cumplir con este objetivo requería contar con una serie histórica de consumo de carbón mineral. La inexistencia de información estadística anterior a la década de 1930 obligó a utilizar fuentes indirectas. La estimación del consumo aparente de carbón (producción más el neto del comercio exterior) aparecía como una alternativa. En Folchi y Rubio (2008) y Rubio et al. (2010) se ha aplicado esta metodología en la reconstrucción de series para América Latina a partir de las estadísticas de comercio de los países proveedores. En el caso de Uruguay, este procedimiento presenta deficiencias porque no discrimina el carbón destinado al abastecimiento de los buques en el registro de las importaciones, especialmente entre fines del siglo XIX y las primeras décadas del siglo XX, fenómeno de magnitud considerable en una economía pequeña. Este trabajo procura sortear estas limitaciones combinando el uso de fuentes nacionales con estadísticas de comercio exterior de los principales proveedores. El resultado es una serie de consumo de carbón mineral desde 1879 hasta el presente.

El análisis del auge y ocaso del carbón mineral como fuente energética en Uruguay aporta información para entender sus orígenes como alternativa a la leña y su desplazamiento por la fuerza arrolladora del petróleo. En tal sentido, complementa esfuerzos anteriores que encararon, en términos generales, la transición desde la energía orgánica a la fósil ${ }^{4}$. Los resultados que se presentan en este artículo permiten discutir la dinámica de la transición del carbón al petróleo en Uruguay, sus determinantes y sus especificidades en el contexto regional y en contraste con los comportamientos europeo y norteamericano ${ }^{5}$.

Luego de esta introducción, en el apartado 2, se presenta de manera sintética la transición energética como categoría analítica y su aplicación al caso uruguayo. Las decisiones metodológicas tomadas para construir una serie de consumo de carbón mineral para el período 1879-2011 se presentan en el apartado 3. En el apartado 4,se analiza el comportamiento del consumo agregado del carbón y se describe el proceso de transición que llevó del auge al ocaso de este energético. En el apartado 5, se buscan explicaciones a tal comportamiento a partir de su transformación como fuente primaria para la producción de otras formas de energía (gas, electricidad) y de su utilización directa por la industria manufacturera y el ferrocarril. El apartado 6 introduce tres condicionantes que impulsaron a tomar decisiones sobre las fuentes energéticas que se debían utilizar: alteraciones en los precios relativos y el costo de los fletes, innovaciones tecnológicas y factores institucionales.

\footnotetext{
4 Véanse Bertoni y Román (2006 y 2008) y Bertoni (2011).

5 Estudio realizado en Folchi y Rubio (2006) y Rubio y Folchi (2012).
} 
Las conclusiones se ordenan en el apartado 7. Finalmente, en el apartado 8, se presentan las fuentes consultadas. Las referencias se incluyen en el apartado 9. El artículo incluye, además, un apéndice con las series históricas de carbón estimadas.

\section{LAS TRANSICIONES ENERGÉTICAS}

Los procesos de transición energética han constituido un factor crucial del "crecimiento económico moderno». La característica fundamental radica en la sustitución de portadores tradicionales - base energética orgánica- por portadores modernos — base energética fósil-, que al tiempo de permitir formas de uso más flexibles y eficientes, acompañan e inducen transformaciones en la estructura económica, en las formas de vida de las sociedades humanas y en el medioambiente.

Dos tendencias dominantes en la evolución de largo plazo son: a) un incremento en el uso de la energía y b) un cambio en la estructura del consumo ${ }^{6}$. Aunque estos procesos se observan a escala global, es posible identificar distintos ritmos en la medida en que las necesidades energéticas constituyen una demanda derivada y, por ende, responde al nivel de desarrollo de las comunidades. La literatura resalta que existe una estrecha asociación entre el crecimiento económico y la demanda de energía, al mismo tiempo que enfatiza que no se trata de una relación lineal ${ }^{7}$. Por ello, es importante indagar en las especificidades que adopta la transición energética.

En Uruguay, la transición energética tiene la particularidad de haber sido un proceso de sustitución de fuentes orgánicas autóctonas por fuentes de energía fósiles foráneas (ya que no posee yacimientos de carbón, petróleo y gas), lo que dio lugar a crecientes niveles de dependencia energética. La demanda de combustibles fósiles ha estado condicionada por fuerzas originadas en la dinámica productiva, el proceso de urbanización y las transformaciones en los hábitos de consumo.

El proceso de cambio estructural y las características que adoptó la inserción internacional de la economía promovieron cambios en el uso de la energía. La internalización de innovaciones de carácter genérico, tales como el transporte ferroviario, la mecanización de las actividades manufactureras y el sistema técnico asociado a la electricidad, estimularon la demanda de energía fósil.

Uruguay asistió a un temprano y acelerado proceso de urbanización; esto desvinculó a un número creciente de la población de las fuentes de provisión energética tradicionales (leña, especialmente) y aproximó a estos sujetos a

\footnotetext{
${ }^{6}$ Cf. Stevens (2000).

7 Véanse Reynolds (1996), Stern y Cleveland (2004) y Gales et al. (2007).
} 
artefactos modernos que demandaban formas también modernas de energía (cocinas, estufas, calefactores, refrigeradores, transporte automotor, etc.) y a nuevos hábitos de consumo energético.

La transición energética, aunque se inicia en las postrimerías del siglo XIX, es un fenómeno típico del siglo XX. Una vez iniciado el proceso, su ritmo y la forma en que se procesó el pasaje del carbón al petróleo se vio condicionado por los fenómenos descritos más arriba, pero también por factores que provenían del exterior, especialmente los problemas de abastecimiento durante los conflictos bélicos, los movimientos en los precios relativos de los energéticos y los cambios de hegemonía a escala global.

\section{CONSTRUCCIÓN DE UNA SERIE DE CONSUMO DE CARBÓN EN EL URUGUAY: UN «ROMPECABEZAS»}

Construir una serie continua de consumo de carbón desde sus orígenes supuso enfrentarse a un conjunto de dificultades estadísticas y recurrir a diversas fuentes de información.

La inexistencia de series oficiales de consumo para el período anterior a 1965 constituye una primera dificultad. Entonces, se utilizó el cálculo realizado por Oxman (1961) para cubrir hasta 1937 y las estimaciones para el período anterior se llevaron a cabo a partir de las cifras de comercio exterior de carbón mineral que implicaron, a su vez, nuevos retos.

\subsection{OFERTA BRUTA DE CARBÓN (1965-2011)}

En 1965 comienza a elaborarse el Balance Energético Nacional (Dirección Nacional de Energía, DNE), que brinda información de la oferta bruta por fuente de energía primaria. Estas cifras son las que se utilizaron hasta el último año disponible: 2011.

\subsection{Consumo bruto de carbón (1937-1965)}

Desde 1937 hasta 1960 se recurre a Oxman (1961), que presenta una estimación del consumo bruto de carbón tomando como referencia datos de la Administración Nacional de Combustibles, Alcohol y Portland (ANCAP) y de la Comisión Económica para América Latina (CEPAL). Estas cifras incluirían la variación de existencias ${ }^{8}$.

Para los cuatro años en que no se cuenta con datos de consumo, 1961-1964, se llevó a cabo la estimación del mismo aplicando la tasa de variación de las

${ }^{8}$ Los trabajos de Oxman constituyeron materiales de referencia para la CEPAL durante las décadas de 1950 y 1960. 
importaciones de carbón — tomado de los Anuarios Estadísticos- al valor de 1960.

\subsection{Consumo aparente de carbón (1879-1937)}

Para el período previo a 1937, se estimó el consumo aparente de carbón considerándolo como consumo doméstico. Esta metodología es de recibo en la literatura y, en particular, para el estudio de los procesos de transición energética en América Latina9 9

Uruguay, al no disponer de yacimientos de carbón mineral, siempre ha debido recurrir a su importación, y las estadísticas de comercio exterior se convierten en fuente de información imprescindible. No obstante, las cifras presentan dificultades para aproximarse al consumo doméstico porque se registraban como importaciones partidas de carbón utilizado para abastecer a los buques del puerto de Montevideo y que, por lo tanto, no podía considerarse parte de la oferta energética. Este artículo plantea una propuesta para resolver ese problema apoyándose en el contraste de los registros de las importaciones uruguayas de carbón (publicadas en los anuarios estadísticos) y de su contracara, es decir, las exportaciones desde los principales socios comerciales (disponibles en los anuarios de comercio exterior de estos países).

Los primeros registros que aparecen en los anuarios estadísticos comprenden importaciones desde 1879. Si bien, para años anteriores, existen cifras de comercio de carbón, se ha privilegiado la homogeneidad de las fuentes antes que prolongar la serie unos pocos años ${ }^{10}$. Por otra parte, los niveles de importación adquirieron una dimensión importante, hacia finales de la década de 1870, y el foco de este estudio está más orientado a lo que sucedió a principios del siglo XX, con la dinámica de la transición del carbón al petróleo ${ }^{11}$.

El carbón mineral del Reino Unido, que hasta la primera guerra mundial fue el principal abastecedor, representó más del $90 \%$ de todo el que llegaba al puerto de Montevideo (el restante provenía, principalmente, de Estados Unidos y de reexportaciones de Argentina). La comparación entre la fuente doméstica y la externa permitió capturar la magnitud del carbón mineral que llegaba al puerto para abastecer a los buques y que, por tanto, no constituía

9 Véanse Folchi y Rubio (2008) y Rubio et al. (2010).

${ }^{10}$ Hemos ubicado tres fuentes con datos para años previos. Vaillant (1873, p. 50) presenta un registro para 1869 bajo la denominación de «carbón de tierra y madera para quemar» y expresado en valor monetario. La Dirección General de Estadística (1877, p. 201) presenta datos de importación de carbón, en toneladas, entre 1872 y 1874: 26.381 (1872), 25.228 (1873) y 15.419 (1874). Acevedo (1933, p. 713) ofrece cifras de consumo por habitante de carbón de piedra, en kilogramos y valor, para $1872-1875$.

${ }^{11}$ En 1875, se consumían 16.135 toneladas de carbón (calculado a partir de las cifras de Acevedo [1933, p. 713]), menos de un quinto del primer dato que se estimó para 1879 (95.648 t). 


\section{GRÁFICO 1}

EFECTO BUNKERING: COMERCIO DE CARBÓN EN TONELADAS, 1879-1930

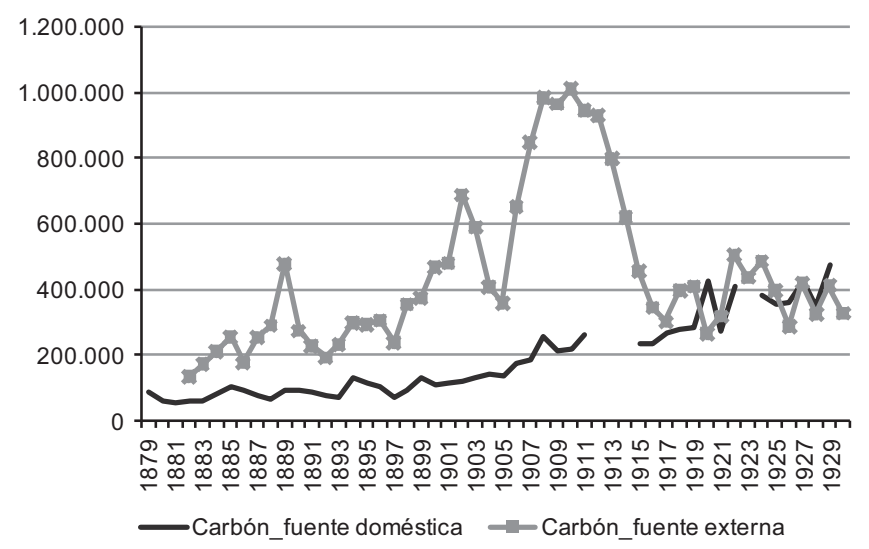

Fuentes: Carbón serie fuente doméstica: DGE: anuarios estadísticos; Carbón serie fuente externa: Statistical Office of the Customs and Excise Department.

consumo doméstico, pero que es difícil discriminar en los registros estadísticos nacionales.

La diferencia entre lo que era para consumo interno y lo arribado al puerto tenía como objetivo el reabastecimiento de los buques (denominado, por las estadísticas, "carbón de trasbordo» o «carbón para bunkering»), o el reembarco hacia otras regiones como Argentina, Paraguay o la frontera con Río Grande ${ }^{12}$. Montevideo no solo fue durante décadas la entrada a la región rioplatense, sino la escala preferida de muchas líneas, lo que la convirtió en una de las estaciones carboneras más importantes de América del Sur.

Ante tal problemática, es pertinente comparar las importaciones de carbón mineral desde el Reino Unido (fuentes domésticas) con las cifras de exportaciones de carbón mineral hacia Uruguay que surgen de los anuarios de comercio exterior del Reino Unido (fuentes externas), a los efectos de estimar el consumo aparente ${ }^{13}$. En el Gráfico 1 están representadas ambas series y ahí se observa una brecha significativa hasta 1916. Esto se explica por el carbón que salía del Reino Unido con destino a Montevideo - y, por

12 Según Labraga et al. (1991, p. 36), en 1876, de las 73.900 t de carbón que se importaron, dos tercios se destinaban al abastecimiento de los buques y un tercio al consumo interno.

${ }^{13}$ Las cifras de exportaciones de carbón mineral hacia Uruguay que surgen de los anuarios de comercio exterior del Reino Unido (Statistical Office of the Customs and Excise Department) forman parte de la base de datos del proyecto de investigación Importaciones y modernización económica en América Latina, 1890-1960 (BEC 2003-0190) dirigido por Albert Carreras en la Universidad Pompeu Fabra, Barcelona. 
tanto, figura en los anuarios estadísticos británicos—cuya finalidad era abastecer los buques del puerto. Las estadísticas nacionales consideraban ese carbón «en tránsito» y solo se registraba el destinado al consumo doméstico, en la medida en que era el único que estaba gravado por aranceles aduaneros.

Hasta 1916, el carbón importado con destino al consumo interno pagaba, por concepto de derecho de aduana, un $6 \%$ por tonelada, mientras que el "carbón que no se destinara para consumo interno estaba exento" (cabe interpretar que este es carbón para buques y, quizás, reexportación). En 1916 se modifica el régimen y el carbón importado queda exento de todo derecho de aduana o impuestos adicionales y el carbón que se moviliza en el puerto pasa a pagar derecho portuario ${ }^{14}$.

Por tanto, el carbón que no tenía por destino el consumo interno pasó a pagar, desde 1916, 0,20 pesos por tonelada. En la medida en que todo el carbón estaba gravado con el mismo derecho portuario, los anuarios estadísticos no discriminan en sus registros-desde entonces- las cantidades de carbón destinado al consumo doméstico de aquel que es para provisión de los buques.

Las dificultades emergentes de este cambio en la registración obligaron a asumir supuestos para estimar el consumo doméstico de carbón a partir de las importaciones. Se ha manejado la siguiente hipótesis: antes de 1916, se considera que únicamente el carbón para consumo interno pagaba derecho de aduana, mientras que el destinado a los buques estaba exento; a partir de dicho año, se elimina el pago del derecho de aduana al carbón para consumo interno, y se establece el pago del derecho portuario para todo el carbón, sea para consumo interno o para los buques. De esta manera, desde 1879 hasta 1915 , las cifras de carbón mineral para consumo interno pueden obtenerse directamente de las importaciones registradas, entendiendo que solo se registraba el carbón que pagaba algún tipo de derecho aduanero.

A partir de 1916, es lógico pensar que la Dirección General de Estadísticas (DGE) comienza a registrar el total de importación de carbón mineral sin discriminar su fin. Esto genera una dificultad para la estimación que permanece hasta 1927, cuando comienzan a registrarse en los anuarios estadísticos cifras correspondientes al concepto «exportaciones de carbón» $\mathrm{y}$, a partir de 1934, se especifica un rubro denominado «exportación de carbón para buques». De esta manera, para el período posterior a 1927 es posible obtener el consumo aparente de carbón con solo restar las exportaciones de carbón del total de importaciones.

Queda explicar cómo se estimó el consumo aparente entre 1916 y 1926. Los anuarios, entre 1905 y 1941, contienen cifras de la carga efectiva de carbón mineral en el puerto, que representaría el total de carbón arribado a Montevideo, sea para consumo interno o para aprovisionamiento de los buques. Si se toma el año 1915, previo a la modificación del régimen fiscal descrito, sería posible aproximarse al porcentaje de carbón mineral destinado a consumo

\footnotetext{
${ }^{14}$ Ley de 8 de julio y decreto reglamentario del 10 de julio (RNLD, 1916, pp. 533 y 543).
} 
interno, calculando la participación de las importaciones sobre el total de carga efectiva de carbón en el puerto. De lo cual resulta que el 59\% del total de carbón que llegaba a Montevideo era para uso interno, mientras que el $41 \%$ se destinaba al abastecimiento de buques. Por otra parte, en 1927 — que, como se dijo, es posible aproximarse al consumo aparente-, el porcentaje destinado al consumo interno asciende al $74 \%$, es decir, disminuye la parte de carbón mineral para abastecer buques. Este fenómeno es coherente con dos procesos simultáneos que experimentaba el país: la sustitución del carbón mineral por el petróleo y la disminución de la importancia del puerto de Montevideo como abastecedor de las flotas del Atlántico sur.

Entonces, tomando la evolución de la carga efectiva de carbón en el puerto, y considerando una disminución lineal del porcentaje de carbón destinado al abastecimiento de buques que contempla la sustitución del carbón por el petróleo entre 1915 y 1927, se estimó el consumo aparente de carbón para dicho período. Este mismo criterio se utilizó para estimar el consumo durante los años de la primera guerra (1912-1914), en los que no fue posible ubicar los datos de importación en los anuarios estadísticos.

\subsection{Empalme y homogeneización de los datos}

En la fase final de construcción de la serie histórica de consumo de carbón como energía primaria, se empalmaron todas las series, desde el presente hasta el origen. A partir de las cifras de la oferta bruta de carbón del Balance Energético Nacional, se ha extrapolado hacia atrás con la tasas de variación del consumo bruto de Oxman (1961) y con la serie de consumo aparente de energía estimada. De esta manera, se asume que la variación de existencias, para la que no se dispone de información antes de 1937, presentó un comportamiento similar al del consumo. El resultado final de la serie histórica entre 1879 y 2011 se presenta en el apéndice (Cuadro A1).

\section{URUGUAY: EL CICLO DEL CARBÓN Y LA TRANSICIÓN FÓSIL}

La serie obtenida se analiza a continuación con el doble objetivo de describir el comportamiento del consumo agregado del carbón en Uruguay en el largo plazo y discutir el proceso en el contexto latinoamericano.

En el Gráfico 2 se observa la evolución del consumo en toneladas y su tendencia (extrayendo el componente cíclico de la serie), donde se identifica claramente un ciclo completo en el consumo de carbón mineral en Uruguay a lo largo de cien años y su virtual abandono en las últimas tres décadas del siglo $\mathrm{XX}^{15}$.

15 La extensión de la serie hasta la actualidad parecería sugerir una incipiente «reutilización» del carbón a partir de la década de 1990; sin embargo su participación está por debajo del 0,04\% de la matriz energética nacional. 


\section{GRÁFICO 2}

CONSUMO DE CARBÓN (EN TONELADAS): SERIE ORIGINAL Y TENDENCIA (ESCALA LOGARÍTMICA), 1879-2011

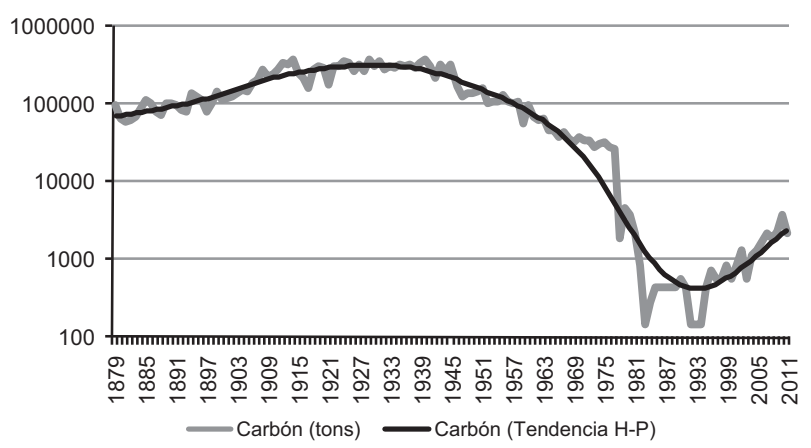

Fuente: apéndice, Cuadro A-1.

Nota: la tendencia de la serie se estimó aplicando el filtro de Hodrick-Prescott.

En los primeros veinte años, se constata un comportamiento fluctuante del consumo de carbón, en torno a las cien mil toneladas anuales, con una leve tendencia al alza. Desde comienzos del siglo XX se observa un extraordinario incremento, del que resulta una triplicación del consumo en vísperas de la primera guerra mundial. Al realizar un análisis por décadas, se observa que el consumo promedio de carbón se incrementó un $70 \%$ entre la última década del siglo XIX y la primera del siglo XX, y vuelve a crecer un $56 \%$ en la segunda década. Con posterioridad, se aprecian aumentos de menor magnitud: un $7 \%$ y un $6 \%$, respectivamente, para los años veinte y treinta. La historia del carbón en Uruguay iniciaba su declive. Así lo refleja, también, la evolución del consumo per cápita, que ya en la década de 1920 comenzó su descenso (Cuadro 1).

En los treinta años siguientes a la primera guerra mundial, el carbón satisfizo los requerimientos energéticos derivados de algunos sectores de demanda rígida (como fue el caso de la Compañía del Gas y de algunas maquinarias en el sector transporte y manufacturero) manteniendo, en términos absolutos, el nivel de consumo alcanzado. No obstante, estos años se caracterizaron por fuertes fluctuaciones derivadas de las guerras, crisis y depresiones a escala global.

Al finalizar la segunda guerra mundial, se produce una caída que retrotrae el nivel a cifras similares a las de principios del siglo y, desde entonces, se asiste a su paulatino abandono como energético hasta llegar a un último escalón negativo al final de la década de 1970, cuando la Compañía del Gas dejó de usarlo como insumo (estos procesos se analizarán con detalle en el apartado 5). 


\section{CUADRO 1}

CONSUMO DE CARBÓN, TOTAL Y POR PERSONA, EN TONELADAS. PROMEDIOS CADA 10 AÑOS (CON EXCEPCIÓN DE 1879-1890 Y 2001-2011)

\begin{tabular}{|l|c|c|}
\hline & Carbón (toneladas) & Kilos por persona \\
\hline $1879-1890$ & 84.364 & 148 \\
\hline $1891-1900$ & 107.172 & 132 \\
\hline $1901-1910$ & 181.776 & 216 \\
\hline $1911-1920$ & 282.779 & 190 \\
\hline $1921-1930$ & 302.103 & 170 \\
\hline $1931-1940$ & 319.941 & 103 \\
\hline $1941-1950$ & 216.277 & 46 \\
\hline $1951-1960$ & 108.987 & 18 \\
\hline $1961-1970$ & 47.681 & 8 \\
\hline $1971-1980$ & 22.571 & 0 \\
\hline $1981-1990$ & 614 & 0 \\
\hline $1991-2000$ & 457 & 1 \\
\hline $2001-2011$ & 1.740 & 172 \\
\hline
\end{tabular}

Fuente: apéndice, Cuadro A-1.

Cuando se compara la evolución del carbón con la dinámica del proceso económico que refleja el comportamiento del producto interno bruto (PIB), se puede señalar que hasta mediados de la segunda década del siglo XX habría existido una fuerte asociación entre el crecimiento del PIB y el consumo de carbón (Gráfico 3). Luego de una década de problemas de abastecimiento que parecen manifestarse en una desvinculación del movimiento de ambas series (1915-1923), la dinámica de crecimiento que se aprecia a nivel agregado de la economía ya no tiene correlación con el carbón. Este fenómeno se hace evidente tras la segunda guerra mundial, recorriendo ambas series derroteros opuestos. Ambas variables presentan una alta correlación (por encima del 80\%) hasta los inicios de la década de 1940, y, a partir de entonces, la dinámica entre ellas se torna negativa ${ }^{16}$.

No parecería arriesgado señalar que la «era del carbón» en Uruguay, en lo que respecta a su aporte como energético asociado al crecimiento económico, debería ubicarse en las primeras décadas del siglo XX.

${ }^{16}$ El análisis de correlación da cuenta del grado de asociación entre dos variables, pero no nos aporta elementos sobre la causalidad de dicha relación. 
GRÁFICO 3

CONSUMO DE CARBÓN Y PIB REAL (ÍNDICE DE $1913=100), 1879-1960($ IZQUIERDA $)$

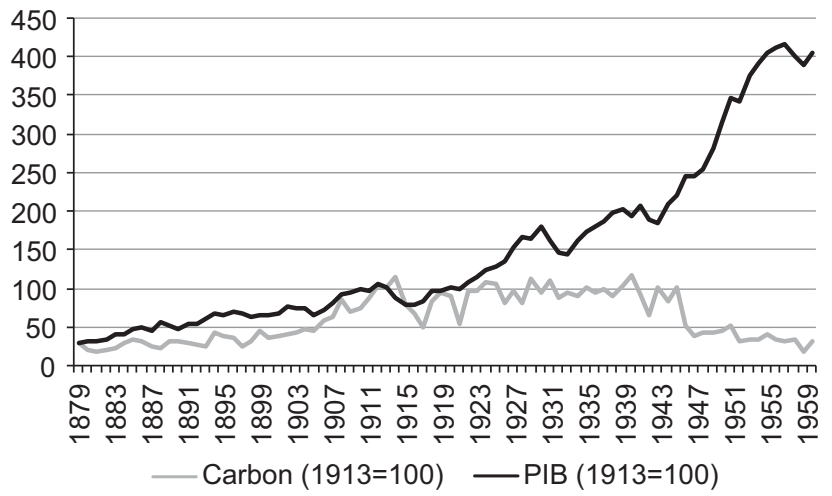

GRÁFICO 4

RATIO CARBÓN (KG) / PIB (MILES DE PESOS DE 2005). SERIE Y TENDENCIA, 1879-1960 (DERECHA)

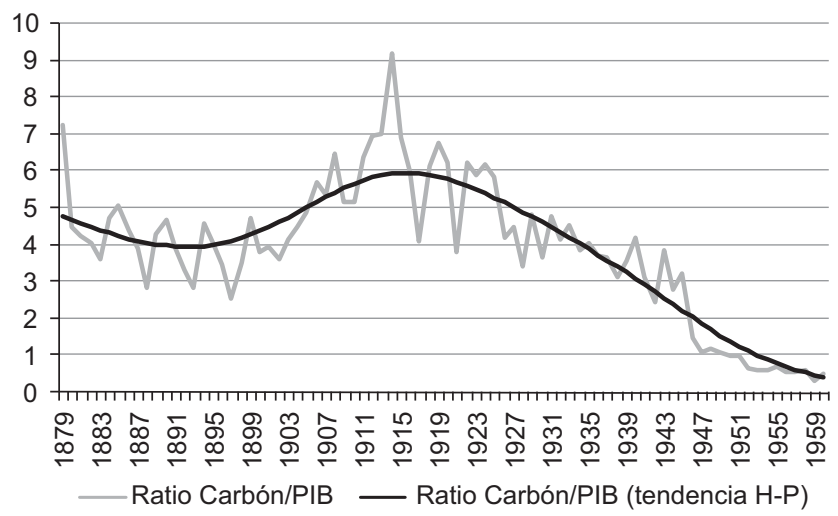

Fuentes: apéndice, Cuadro A-1. PIB de Bonino et al. (2012) en base a Bértola et al. (1998), Bertino y Tajam (1999), Banco de la República Oriental del Uruguay y Banco Central del Uruguay.

Nota: La tendencia de la serie se estimó aplicando el filtro de Hodrick-Prescott. 
La energía necesaria para los procesos de valorización se aportaría crecientemente, después de la primera guerra mundial, por otros portadores. De ahí la caída de la intensidad carbonífera que se aprecia en el Gráfico 4. El análisis de la dinámica de los sectores intensivos en el consumo de carbón aportará evidencia para dar robustez a esta premisa.

La literatura, como se ha señalado, insiste en la sustitución del carbón por el petróleo como fenómeno típico de la transición en las sociedades en las que se asiste a la imposición de la energía moderna.

En el caso de Uruguay, resulta evidente la presencia de este proceso entre 1915 y 1950, cuando se invierte la participación de ambos energéticos (Gráfico 5). El momento clave debe ubicarse a mediados de la década de 1920; no obstante, este proceso de transición no es lineal. Podría interpretarse que, tras el primer síntoma de sustitución, durante la primera guerra mundial, la competencia entre estos dos energéticos solo se dio en algunos ámbitos, y que el avance del petróleo se explica como resultado del surgimiento de nuevas actividades más que por la sustitución del carbón en las ya existentes (el caso paradigmático sería el del transporte automotor). Luego, entre 1930 y 1945, se asiste a un período de estancamiento en las participaciones relativas del carbón y el petróleo; y justo después de la segunda guerra mundial, el petróleo domina la estructura al caer abruptamente el consumo de carbón.

¿Cómo se ubica la dinámica de la transición del carbón al petróleo en el Uruguay, en comparación con este proceso en otras sociedades?

\section{GRÁFICO 5}

TRANSICIÓN ENERGÉTICA: EL «MODELO URUGUAYO», 1879-2011

(PORCENTAJES)

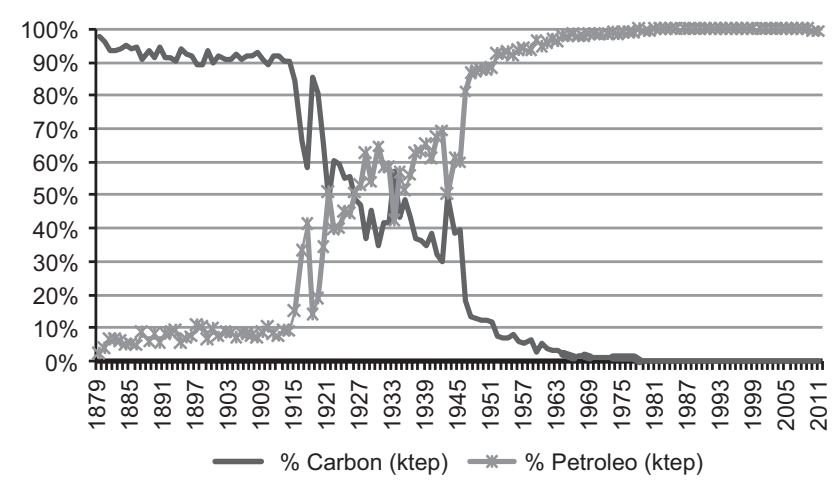

Fuentes: apéndice Cuadro A-1. Serie de petróleo 1879-1882: exportaciones de petróleo desde el Reino Unido a Uruguay (Statitsical Office of the Customs and Excise Department); serie 1882-1965: Bertoni y Román (2008); serie 1965-2011: balance energético (DNE).

Nota: series en toneladas equivalentes de petróleo (TEP) utilizando la conversión 1 TEP = 1,43 t de carbón. 
Diversos trabajos han descrito las características de esta transición ${ }^{17}$ y resaltan la existencia de dos modelos básicos: el de Estados Unidos y el de Europa occidental. El primero se caracterizaría por un temprano abandono del carbón (durante la primera mitad del siglo XX) y el segundo por la permanencia de este energético como portador dominante hasta la década de 1960. En cualquier caso, estos modelos muestran un comportamiento inercial muy importante que lleva a que, una vez iniciada la transición, esta se complete sin retrocesos o «demoras».

Los estudios sobre la transición energética en países en desarrollo cuestionan que estos procesos puedan caracterizarse a partir de dichos modelos. Para América Latina, Folchi y Rubio (2006) analizan el fenómeno de la transición en las energías fósiles y encuentran que la región no siguió ninguno de los dos patrones clásicos y que presenta diversas trayectorias. Se plantea que el fenómeno es más temprano y mucho más oscilante en los casos latinoamericanos que en Europa y Estados Unidos. Además, la velocidad con la cual se da este proceso es muy variable en la región, y en Rubio y Folchi (2012, p. 54) se identifican cuatro modelos de transición. El «modelo uruguayo» sería similar al detectado en Chile y Colombia, y se caracterizaría por ciclos de retroceso y recuperación del carbón, sin que se imponga con claridad la supremacía del petróleo hasta muchos años después de iniciada la transición.

La dinámica del carbón, a partir del trabajo empírico propuesto en este artículo, confirmaría esa peculiaridad del modelo uruguayo que identificaron Folchi y Rubio a partir del uso de otras fuentes. Una caída de la participación del carbón en la matriz energética durante la primera posguerra (del orden del $50 \%$ ) fue seguida de veinte años de fluctuaciones, hasta la segunda guerra mundial. Y solo a partir de entonces se completa la transición al petróleo (Gráfico 5).

No obstante, la nueva serie construida ofrece información relevante que corrige de manera sustantiva los niveles de consumo manejados por Rubio y Folchi (2012) ${ }^{18}$. Al tener en cuenta el efecto bunkering (Gráfico 1), el consumo per cápita de carbón de Uruguay se reduce dramáticamente y, aunque el país no abandona su lugar entre los cuatro mayores consumidores de energía moderna en la región, con la nueva información pasaría del primero al cuarto puesto en el ránking elaborado por dichos autores (Cuadro 2).

Teniendo en cuenta que el consumo de energía moderna se utiliza en algunos trabajos como indicador de modernización económica ${ }^{19}$, esta corrección no es trivial y constituye un aporte a la mejor comprensión del grado de modernización de la economía uruguaya.

\footnotetext{
17 Véanse Rubio y Folchi (2012) y Folchi y Rubio (2006).

18 Ya en Rubio et al. (2010, nota 63) se advierte de este fenómeno.

19 Por ejemplo, Rubio et al. (2010) y Yáñez et al. (2008).
} 


CUADRO 2
URUGUAY: CONSUMO DE ENERGÍA MODERNA PER CÁPITA (TEP CADA 1.000
\begin{tabular}{|l|c|c|c|c|c|}
\hline HABITANTES) \\
\hline & $\begin{array}{c}\text { Rubio y } \\
\text { Folchi (R\&F) }\end{array}$ & $\begin{array}{c}\text { Bertoni y } \\
\text { Román (B\&R) }\end{array}$ & $\begin{array}{c}\text { Ratio } \\
\text { R\&F/ B\&R }\end{array}$ & $\begin{array}{c}\text { Uruguay } \\
\text { en ránking } \\
\text { regional (R\&F) }\end{array}$ & $\begin{array}{c}\text { Uruguay en } \\
\text { ránking regional } \\
\mathbf{( B \& R )}\end{array}$ \\
\hline 1890 & 278,6 & 109,6 & 2,5 & 1 & 4 \\
\hline 1900 & 360,3 & 100,3 & 3,6 & 1 & 4 \\
\hline 1913 & 449,8 & 201,7 & 2,2 & 1 & 4 \\
\hline 1925 & 287,2 & 277,7 & 1,0 & 1 & 4 \\
\hline
\end{tabular}

Fuentes: Rubio y Folchi (2012), Bertoni y Román (2008) y Cuadro A-1 del apéndice.

\section{BUSCANDO PISTAS. LOS SECTORES INTENSIVOS EN EL CONSUMO DE CARBÓN}

Para contribuir a explicar la dinámica del carbón y la transición al petróleo, en este apartado se aporta un panorama de los usos del carbón, cuantificando el consumo por sectores económicos identificados como «grandes consumidores» de este energético.

Dado que el uso que hicieron los hogares del carbón fue absolutamente marginal en el país, la estrategia consistió en concentrarse en analizar la evolución del uso del carbón para la producción de otras formas de energía secundaria (gas y electricidad) y su aporte como insumo en la actividad de la industria y el ferrocarril.

La información disponible ha permitido reconstruir parcialmente el consumo en estos cuatro sectores. Para dimensionar su representatividad como consumidores de carbón, se estimaron las toneladas requeridas por cada uno en el período 1908-1911 y se comparó el resultado con el consumo agregado promedio anual de esos cuatro años (Cuadro 3).

En el caso de la industria, se realizó una estimación mediante la combinación de información de los censos industriales de 1908 y 1936 para la construcción, las actividades manufactureras y la industria extractiva ${ }^{20}$. El cálculo se realizó a partir de la capacidad instalada de la industria, suponiendo que si en 1936 la potencia instalada de vapor $(9.049 \mathrm{hp})$ requería como insumo 64.412 t de carbón, en 1908 los 16.750 hp instalados habrían requerido $119.222 \mathrm{t}^{21}$.

El consumo de carbón para generación eléctrica en 1910 se obtuvo de los anuarios estadísticos. En cuanto al consumo para la producción de gas, se

${ }^{20}$ Se excluye el servicio público de suministro de agua (bombeo).

21 Esto supone un coeficiente técnico constante, lo que podría sesgar a la baja la cifra de 1908. 


\section{CUADRO 3}

CONSUMO DE CARBÓN MINERAL TOTAL Y DE LOS PRINCIPALES

SECTORES, 1908-1911

\begin{tabular}{|l|c|c|c|c|c|c|}
\hline & $\begin{array}{c}\text { Industria } \\
\mathbf{( 1 9 0 8 )}\end{array}$ & $\begin{array}{c}\text { Gas } \\
\mathbf{( 1 9 1 1 )}\end{array}$ & $\begin{array}{c}\text { Electricidad } \\
\mathbf{( 1 9 1 0 )}\end{array}$ & $\begin{array}{c}\text { Ferrocarriles } \\
\mathbf{( 1 9 1 0 )}\end{array}$ & Subtotal & $\begin{array}{c}\text { Total } \\
\text { (promedio } \\
\mathbf{1 9 0 8 - 1 9 1 1}\end{array}$ \\
\hline Toneladas & 119.229 & 16.031 & 10.930 & 43.988 & 190.177 & 227.417 \\
\hline Participación & $52 \%$ & $7 \%$ & $5 \%$ & $19 \%$ & $84 \%$ & $100 \%$ \\
\hline
\end{tabular}

Fuente: véase el apartado 5.

partió de las cifras de consumo de carbón para 1933 (anuarios estadísticos) y del total de metros cúbicos de gas producidos anualmente entre 1911 y $1930^{22}$, se supuso que la cantidad de carbón consumida en 1933 no habría tenido cambios sustantivos respecto a la de 1930 y, asumiendo el mismo coeficiente técnico, se consideró plausible que hacia 1911 el consumo se situara en $16.031 \mathrm{t}$ anuales (véase el subapartado 5.2).

Finalmente, para dimensionar la importancia de los ferrocarriles, se recurrió al consumo requerido para el funcionamiento de las locomotoras de una de las compañías ferroviarias, The Central Uruguay Railway Company, a partir de la información que reportan las memorias. Esta empresa era la más importante del país y, hacia 1913, controlaba el $60 \%$ de las vías férreas ${ }^{23}$.

Como resumen, hacia 1908-1911, el uso de carbón mineral por estos cuatro sectores habría representado el $84 \%$ del consumo total. El principal sector consumidor era la industria (52\%), seguido del transporte ferroviario $(19 \%)$, mientras que el carbón para la producción de gas y de electricidad representaba el $12 \%$ del total (Cuadro 3).

Las dificultades para obtener información cuantitativa uniforme que ilustre el comportamiento de los sectores en el período relevante de la participación del carbón en la matriz energética llevaron a complementar la indagatoria con testimonios y fuentes cualitativas diversas.

\subsection{Producción de energía eléctrica}

Según las memorias de las Usinas Eléctricas del Estado (UEE), en vísperas de la primera guerra mundial la empresa consumía más de 25.000 t

\footnotetext{
22 En Bertino et al. (2005).

${ }^{23}$ Las demás vías eran propiedad de Midland Uruguay Railway (20\%) y de empresas más pequeñas, para las que no se cuenta con información directa. Cf. Díaz (2011) y Barrán y Nahum (1978).
} 
de carbón mineral en sus plantas generadoras de energía eléctrica en Montevideo (en torno al $8 \%$ del consumo total de esos años) ${ }^{24}$.

Las dificultades de abastecimiento durante el conflicto bélico obligaron a tomar medidas de carácter extraordinario, tales como la utilización de leña y otros combustibles orgánicos y, finalmente, las autoridades resolvieron convertir los quemadores de las calderas para poder utilizar fueloil. Esta decisión técnica y los cambios en el escenario económico mundial indujeron una transformación decisiva en las UEE, al sustituirse el carbón por el petróleo a comienzos de la década de 1920 (Cuadro 4).

No obstante, habría una «vuelta al carbón» durante las décadas de 1930 y 1940. La central termoeléctrica José Batlle y Ordóñez — puesta en funcionamiento en 1932-fue diseñada para utilizar fueloil o carbón indistintamente. Esto permitió dar cierto margen a la empresa para afrontar las dificultades emergentes de la gran depresión y, especialmente, las restricciones en materia de divisas, ya que el petróleo y el carbón provenían, principalmente, de áreas monetarias distintas.

Aunque no fue posible encontrar información directa referida al consumo de combustibles en unidades físicas durante los años treinta ${ }^{25}$, se pudo acceder a dos fuentes secundarias. Una es la publicación de la ANCAP, empresa estatal que, desde 1937 y hasta finalizar la segunda guerra mundial, abasteció a todos los organismos públicos de carbón mineral y que registra datos de «aprovisionamiento de combustibles a la UTE» (Cuadro 5) ${ }^{26}$. La otra fuente es Oxman (1961), que ofrece información, basada en documentación de la UTE, que cubre desde 1935 hasta 1960, cuando la ANCAP dejó de ser la única empresa proveedora de carbón para la UTE (Cuadro 6).

Con base en dichas fuentes se constata que el carbón volvió a participar en la generación de energía eléctrica durante la década de 1930; sin embargo, su regreso fue efímero. En la inmediata posguerra, el petróleo sustituyó definitivamente al carbón en la generación termoeléctrica. El petróleo y la fuerza hidráulica compartieron desde mediados del siglo XX el aporte primario de energía para la generación, desplazando completamente al carbón.

En síntesis, el carbón mineral acompañó el crecimiento del sector eléctrico hasta la primera guerra mundial. Tras una parcial desvinculación de, aproximadamente, una década y media, en los treinta volvió a contribuir a la generación; pero, después de la segunda guerra mundial, dejó de participar prácticamente en esa función. Como se verá en el apartado 6, razones de orden tecnológico (eficiencia) y los precios relativos de los combustibles podrían contribuir a explicar este fenómeno.

\footnotetext{
${ }^{24}$ Las UEE disfrutaron el monopolio de la generación, transmisión y distribución desde 1912.

25 Solo se registra en valores monetarios la incidencia del gasto en combustibles, sin discriminar energéticos, en los costos de producción.

${ }^{26}$ UTE es la sigla de Usinas y Teléfonos del Estado, la nueva empresa pública que sustituyó a las Usinas Eléctricas del Estado (UEE) en la década de 1930.
} 


\section{CUADRO 4}

USINA ELÉCTRICA DE MONTEVIDEO. CONSUMO DE COMBUSTIBLES (TONELADAS), 1906-1930

\begin{tabular}{|c|c|c|c|}
\hline & Carbón mineral & Petróleo (fueloil) & Leña \\
\hline 1906 & 6.034 & & \\
\hline 1907 & 5.215 & & \\
\hline 1908 & 7.757 & & \\
\hline 1909 & 11.624 & & \\
\hline 1910 & 10.930 & & 45 \\
\hline 1911 & 13.914 & & 58 \\
\hline 1912 & 18.946 & & 94 \\
\hline 1913 & 22.982 & & 107 \\
\hline 1914 & 26.491 & & 115 \\
\hline 1915 & 27.820 & & 113 \\
\hline 1916 & 14.928 & 11.761 & 45 \\
\hline 1917 & & 27.319 & \\
\hline 1918 & 14.047 & 15.346 & 15.401 \\
\hline 1919 & 28.895 & 10.071 & 1.882 \\
\hline 1920 & 1.003 & 39.419 & \\
\hline 1921 & 4.592 & 36.240 & 471 \\
\hline 1922 & & 41.206 & \\
\hline 1923 & & 44.184 & \\
\hline 1924 & & 47.389 & \\
\hline 1925 & & 47.507 & \\
\hline 1926 & & 48.579 & \\
\hline 1927 & & 54.831 & \\
\hline 1928 & & 61.162 & \\
\hline 1929 & & 69.034 & \\
\hline 1930 & & 79.241 & \\
\hline
\end{tabular}

Fuente: anuarios estadísticos de la DGE. 


\begin{tabular}{|c|c|c|c|c|c|}
\hline \multicolumn{6}{|c|}{$\begin{array}{c}\text { CUADRO } \mathbf{5} \\
\text { ANCAP: APROVISIONAMIENTO DE COMBUSTIBLES A LA UTE (TONELADAS), } \\
1938-1947\end{array}$} \\
\hline & Carbón mineral & Petróleo (fueloil) & Diésel oil & Leña & Otros \\
\hline 1938 & 67.230 & 43.264 & 7.160 & \multirow{10}{*}{2.085} & \multirow{10}{*}{$\begin{array}{l}88.507 \\
83.300 \\
13.068\end{array}$} \\
\hline 1939 & 95.694 & 48.274 & 7.537 & & \\
\hline 1940 & 109.141 & 45.183 & 7.691 & & \\
\hline 1941 & 48.238 & 50.549 & 9.297 & & \\
\hline 1942 & 46.171 & 48.203 & 8.775 & & \\
\hline 1943 & 113.008 & 47.274 & 8.731 & & \\
\hline 1944 & 76.747 & 63.835 & 7.565 & & \\
\hline 1945 & 108.325 & 85.831 & 9.824 & & \\
\hline 1946 & & 96.156 & 11.930 & & \\
\hline 1947 & & 53.370 & 15.457 & & \\
\hline
\end{tabular}

Fuente: Boletín Estadístico de la ANCAP (1948).

\subsection{La Compañía del Gas}

El carbón mineral, desde las últimas décadas del siglo XIX, constituyó el insumo energético a partir del cual se llevó a cabo la producción de gas para el alumbrado de la ciudad de Montevideo. Aunque en la capital operaba una usina desde antes, esta utilizó residuos de animales, grasas y huesos para la fabricación de gas. La transferencia de la empresa a The Montevideo Gas Company Ltd. marcó un cambio fundamental, tanto en el tipo de servicio ofrecido como en la tecnología asociada a la producción del gas.

Hacia 1900, el uso de gas para alumbrado empezaría a perder protagonismo ante el avance de la energía eléctrica, pero amplió su participación en los hogares para la cocción, la calefacción y el calentamiento de agua. Según Maeso (1910, p. 57), en 1908 había en Montevideo 16.536 servicios en operación, repartidos entre «instalaciones domiciliarias y casas de negocios». Según el censo de 1908, en Montevideo había un total de 36.080 viviendas, incluyendo casas particulares y de negocios, por lo que aquella cifra representaba una cobertura de $46 \%$. Si bien no se cuenta con información sobre la evolución de los suscriptores en los años siguientes, es posible identificar una ampliación de la actividad de la Compañía del Gas a través de su producción. Según Bertino et al. (2005, p. 293), entre 1911 y 1930 la compañía del gas aumentó su producción de cinco a nueve millones de metros cúbicos al año. 


\section{CUADRO 6}

CONSUMO DE COMBUSTIBLES PARA LA PRODUCCIÓN DE ELECTRICIDAD (TONELADAS), 1935-1960

\begin{tabular}{|l|c|c|c|}
\hline & \multicolumn{2}{|c|}{ Centrales a vapor } & Centrales Diesel \\
\hline & Carbón & Fueloil & Diésel oil \\
\hline 1935 & 52.865 & 41.218 & 4.879 \\
\hline 1940 & 90.016 & 47.640 & 7.242 \\
\hline 1945 & 143.331 & 68.513 & 8.813 \\
\hline 1946 & 13.830 & 102.731 & 10.399 \\
\hline 1947 & & 50.926 & 13.999 \\
\hline 1948 & & 48.892 & 17.830 \\
\hline 1949 & & 26.726 & 19.423 \\
\hline 1950 & & 27.176 & 21.401 \\
\hline 1951 & & 83.223 & 23.914 \\
\hline 1952 & & 66.664 & 26.751 \\
\hline 1953 & & 71.910 & 32.084 \\
\hline 1954 & 145 & 69.182 & 36.753 \\
\hline 1955 & 17.431 & 83.799 & 26.440 \\
\hline 1956 & & 175.737 & 19.081 \\
\hline 1957 & 7.447 & 181.627 & 18.340 \\
\hline 1958 & & 145.653 & 20.119 \\
\hline 1959 & & 303.500 & 22.089 \\
\hline 1960 & & 175.899 & \\
\hline & & & \\
\hline & & & \\
\hline
\end{tabular}

Fuente: Oxman (1961, p. 73, Cuadro XIII).

Se cuenta con información referente a los metros cúbicos de gas consumidos en Montevideo entre 1933 y $1939^{27}$. Por su parte, una publicación de la Comisión de Inversiones y Desarrollo Económico (CIDE) ofrece, desde 1937, una serie homogénea del carbón carbonizado para producir gas (Cuadro 7). A partir de esta información, se realizó una estimación del consumo de carbón por parte de la Compañía del Gas en 1911, como se describió al comienzo de este apartado. Entonces, la producción de gas representaba el $7 \%$ del total del consumo aparente de carbón.

\footnotetext{
${ }^{27}$ Sintesis Estadística, DGE.
} 
AUGE Y OCASO DEL CARBÓN MINERAL EN URUGUAY. UN ANÁLISIS HISTÓRICO DESDE FINES DEL SIGLO XIX HASTA LA ACTUALIDAD

\section{CUADRO 7}

CARBÓN CARBONIZADO POR LA COMPAÑÍA DEL GAS Y DIQUE SECO DE MONTEVIDEO, 1933-1962

\begin{tabular}{|l|c|c|c|}
\hline Año & Toneladas & Año & Toneladas \\
\hline 1933 & 28.855 & 1948 & 41.866 \\
\hline 1934 & 28.130 & 1949 & 43.465 \\
\hline 1935 & 29.204 & 1950 & 50.619 \\
\hline 1936 & 30.025 & 1951 & 52.321 \\
\hline 1937 & 31.826 & 1952 & 54.299 \\
\hline 1938 & 33.922 & 1953 & 54.888 \\
\hline 1939 & 31.203 & 1954 & 53.218 \\
\hline 1940 & 31.237 & 1955 & 56.543 \\
\hline 1941 & 32.301 & 1956 & 55.657 \\
\hline 1942 & 29.261 & 1957 & 53.795 \\
\hline 1943 & 31.406 & 1958 & 55.867 \\
\hline 1944 & 33.771 & 1959 & 53.802 \\
\hline 1945 & 36.447 & 1960 & 55.633 \\
\hline 1946 & 35.928 & 1961 & 44.746 \\
\hline 1947 & 40.419 & 1962 & 42.310 \\
\hline
\end{tabular}

Fuente: CIDE (1965, p. 52, Cuadro A).

Nota: las cifras para 1933-1936 se estimaron a partir del coeficiente de eficiencia de 1938.

La ampliación señalada más arriba en el servicio público de gas en Montevideo condujo a un incremento del consumo de carbón. Así, el uso promedio de carbón por parte de la Compañía del Gas representó entre 1933 y 1945 el 10\% del consumo total del país.

En la década siguiente, y debido a la sustitución del carbón por el petróleo y la electricidad en otras actividades, al tiempo que caía el consumo del primero en términos absolutos se incrementaba la participación de la Compañía del Gas como demandante, pasando primero a representar más de la mitad del total consumido y, ya en los años sesenta, alrededor de las tres cuartas partes. Desde 1965, casi la totalidad del carbón mineral importado por el país tuvo como destino la Compañía del Gas; y cuando, en 1978, dicha empresa dejó de utilizar como materia prima el carbón para sustituirlo por la nafta, virtualmente cesó el consumo de este combustible en la matriz energética del país. 


\subsection{Los ferrocarriles}

Hasta la primera guerra mundial, las locomotoras de los ferrocarriles uruguayos consumieron carbón mineral como combustible. Pero, a raíz de las dificultades en el abastecimiento durante el conflicto bélico y del encarecimiento de este insumo, se impuso la necesidad de utilizar otro energético.

A diferencia de las UEE y de gran parte de los establecimientos industriales, que empezaron a utilizar el petróleo desde 1916, en los ferrocarriles, el carbón de piedra, junto a la leña y otros combustibles orgánicos, siguió siendo el combustible básico hasta el final de la primera guerra mundial. En los primeros años veinte, fuentes británicas señalaban que The Central Uruguay Railway Company contaba con un importante número de locomotoras que se habían reconvertido para quemar fueloil. En 1924, 75 máquinas locomotoras utilizaban ese combustible (22 más que el año anterior) y 67 seguían siendo consumidoras de carbón. Gran parte de estas últimas, eran de baja potencia y estaban acercándose al fin de su vida útil, por lo que no iban a ser reconvertidas a petróleo ${ }^{28}$. En dicho año, el fueloil pasó a ser el combustible principal de las locomotoras. Como se observa en el Cuadro 8, el gasto total en combustibles permite dar cuenta de que a comienzos de la década de 1930 la sustitución del carbón por el fueloil se había completado.

Como ya se adelantó, esta compañía ferroviaria solo explotaba el $60 \%$ de la red nacional; por tanto, las cifras manejadas no reflejan lo ocurrido en los Ferrocarriles y Tranvías del Estado, así como en otras pequeñas empresas privadas. Como se deduce del Cuadro 9, elaborado a partir de las memorias de la Administración de los Ferrocarriles y Tranvías del Estado, allí los años treinta parecen constituir el momento clave de transición de un proceso que se consumaría en la inmediata posguerra ${ }^{29}$.

Al concretarse la nacionalización de los ferrocarriles en 1948, la nueva empresa estatal decidió la sustitución gradual de la tracción a vapor (ya en una gran proporción con quemadores a fueloil) por la tracción diésel. La primera etapa se concretó entre 1951 y 1955, y comprendió la dieselización del sistema en general, con excepción de las líneas del litoral (Salto, Cuareim, Artigas y ramal Fray Bentos). La segunda y última etapa para completar la dieselización del sistema se materializó en 1963 con la adquisición de 25 locomotoras de ruta y 14 de maniobras. Cumplida esta última etapa de la

28 Central Uruguay Railway Company, junio de 1924, p. 21.

29 El aparente retorno del carbón en 1948 solo es un efecto estadístico de la nacionalización de las compañías ferroviarias a partir de la adquisición de otras líneas por la Administración de los Ferrocarriles y Tranvías del Estado, lo que llevó a incorporar algunas locomotoras que todavía funcionaban a carbón. 


\begin{tabular}{|c|c|c|c|c|}
\hline & URUGUAY RAII & $\begin{array}{r}\text { CUAD } \\
\text { MPANY. CARBC }\end{array}$ & JMIDO POR LAS & ORAS, 1900-1937 \\
\hline & $\begin{array}{c}\text { Carbón utilizado } \\
\text { (toneladas) }\end{array}$ & $\begin{array}{l}\text { Costo total del } \\
\text { carbón (libras) }\end{array}$ & $\begin{array}{l}\text { Petróleo utilizado } \\
\text { (toneladas) }\end{array}$ & $\begin{array}{c}\text { Costo total del } \\
\text { petróleo (libras) }\end{array}$ \\
\hline 1900 & & 16.945 & & \\
\hline 1901 & & 31.400 & & \\
\hline 1902 & & 30.376 & & \\
\hline 1903 & & 27.591 & & \\
\hline 1904 & & 29.038 & & \\
\hline 1905 & & 28.353 & & \\
\hline 1906 & 27.778 & 31.501 & & \\
\hline 1907 & 33.145 & 47.969 & & \\
\hline 1908 & & 58.965 & & \\
\hline 1909 & & 58.600 & & \\
\hline 1910 & 43.988 & 57.196 & & \\
\hline 1911 & 50.714 & 74.120 & & \\
\hline 1912 & & 82.661 & & \\
\hline 1913 & & 97.413 & & \\
\hline 1914 & & 105.540 & & \\
\hline 1915 & 46.917 & 91.886 & & \\
\hline 1916 & 52.642 & 154.112 & 436 & \\
\hline 1917 & 51.832 & 212.023 & & \\
\hline
\end{tabular}


CUADRO 8 (Cont.)

\begin{tabular}{|c|c|c|c|c|}
\hline & $\begin{array}{l}\text { Carbón utilizado } \\
\text { (toneladas) }\end{array}$ & $\begin{array}{l}\text { Costo total del } \\
\text { carbón (libras) }\end{array}$ & $\begin{array}{l}\text { Petróleo utilizado } \\
\text { (toneladas) }\end{array}$ & $\begin{array}{c}\text { Costo total del } \\
\text { petróleo (libras) }\end{array}$ \\
\hline 1918 & 33.889 & 214.188 & 1.014 & 5.076 \\
\hline 1919 & 49.231 & 324.743 & 459 & 2.202 \\
\hline 1920 & 62.258 & 322.552 & 711 & 3.480 \\
\hline 1921 & 65.560 & 468.781 & 1.354 & 5.782 \\
\hline 1922 & 44.516 & 161.032 & 9.438 & 37.325 \\
\hline 1923 & & 91.001 & & 76.610 \\
\hline 1924 & 24.219 & 65.469 & 35.419 & 116.630 \\
\hline \multicolumn{5}{|l|}{$(\ldots)$} \\
\hline 1931 & & 1.870 & & 155.398 \\
\hline 1932 & & 8 & & 93.766 \\
\hline 1933 & & & & 88.980 \\
\hline 1934 & & & & 97.233 \\
\hline 1935 & & & & 109.312 \\
\hline 1936 & & & & 112.647 \\
\hline 1937 & & & & 111.031 \\
\hline
\end{tabular}


AUGE Y OCASO DEL CARBÓN MINERAL EN URUGUAY. UN ANÁLISIS HISTÓRICO DESDE FINES DEL SIGLO XIX HASTA LA ACTUALIDAD

\section{CUADRO 9}

ADMINISTRACIÓN DE LOS FERROCARRILES Y TRANVÍAS DEL ESTADO. CONSUMO DE CARBÓN, PETRÓLEO Y NAFTA, 1927-1951

\begin{tabular}{|c|c|c|c|}
\hline & Carbón (toneladas) & Petróleo (toneladas) & Nafta (litros) \\
\hline 1927 & 6.012 & & \\
\hline 1928 & 6.334 & & \\
\hline 1929 & 7.923 & 6.289 & \\
\hline 1930 & 8.087 & & 93.020 \\
\hline 1931 & 3.975 & 1.459 .790 & 204.650 \\
\hline 1932 & 214 & 2.511 .598 & 153.231 \\
\hline 1933 & 52 & 2.529 .451 & 127.873 \\
\hline \multicolumn{4}{|l|}{1934} \\
\hline 1935 & 294 & 4.514 .473 & 519.989 \\
\hline 1936 & 339 & 5.458 .056 & 707.574 \\
\hline \multicolumn{4}{|l|}{1937} \\
\hline \multicolumn{4}{|l|}{1938} \\
\hline \multicolumn{4}{|l|}{1939} \\
\hline 1940 & $1.488^{*}$ & 6.342 .170 & 2.553 .317 \\
\hline 1941 & $1.491^{*}$ & 6.679 .731 & 2.727 .153 \\
\hline \multicolumn{4}{|l|}{1942} \\
\hline \multicolumn{4}{|l|}{1943} \\
\hline \multicolumn{4}{|l|}{1944} \\
\hline \multicolumn{4}{|l|}{1945} \\
\hline \multicolumn{4}{|l|}{1946} \\
\hline \multicolumn{4}{|l|}{1947} \\
\hline 1948 & 10.428 & 67.740 .000 & \\
\hline 1949 & 10.954 & 82.323 .000 & \\
\hline 1950 & 8.544 & 83.268 .000 & \\
\hline 1951 & 7.861 & 87.603 .000 & 305.365 \\
\hline
\end{tabular}

Fuente: Administración de los Ferrocarriles y Tranvías del Estado (varios años).

" Incluye leña. 
dieselización, quedaron teóricamente satisfechas las necesidades de tracción y, por lo tanto, se posibilitó la eliminación definitiva del parque a vapor que aún se mantenía en servicio.

La transición del carbón al petróleo en los ferrocarriles uruguayos debe ubicarse en las décadas de 1920 y 1930; y el definitivo ocaso de este energético en dicho sector, en la segunda posguerra.

\subsection{La industria temprana}

A partir de una discusión de los datos revelados en el Censo General de 1908 y en el Censo Industrial de 1936, es posible aproximarse al proceso de sustitución del carbón por el petróleo y, especialmente, por la energía eléctrica como fuentes proveedoras de la fuerza motriz para la industria.

En el Cuadro 10, se presenta la "fuerza motriz instalada» en el sector industrial de Montevideo. A partir de aquí, se supone que los «motores de vapor» (1908) y las "máquinas y turbinas a vapor» (1936) se movían con energía proveniente de la combustión del carbón mineral. Esto oculta la posible sustitución que pudo haberse producido como resultado de la transformación de los quemadores de las calderas para la utilización de fueloil. Solo se consideró maquinaria demandante de derivados del petróleo aquella que aparece identificada como «motores a combustión interna». Este sesgo hace que, posiblemente, la participación del carbón mineral como energético en la industria pueda haber sido algo menor. Pero asumiendo esto, es posible comparar dos escenarios plausibles, ya que en 1908 la participación del petróleo, según otras fuentes, podría considerarse marginal y, en todo caso, en 1936 podría haber una sobreestimación del consumo de carbón, porque el uso del fueloil para alimentar las calderas seguramente estaba más extendido. Por tanto, los datos utilizados podrían considerarse una aproximación al proceso de sustitución del carbón en la industria.

La potencia de los motores industriales que utilizaban carbón cayó casi a la mitad, reduciéndose su participación en el total de la fuerza motriz instalada desde el $73,5 \%$ hasta el $10 \%$ entre 1908 y 1936 (Cuadro 10). De manera paralela, hace su aparición el petróleo, que se utiliza como combustible (el 8,5\% de la potencia instalada en la última fecha, cifra similar a la del carbón). Finalmente, es extraordinario el incremento de los motores eléctricos, que se multiplican por 13,5 hasta representar más del $80 \%$ del total de la potencia instalada en maquinaria industrial.

Entre 1920 y1930, la industria uruguaya creció a una tasa del 5,5\% acumulativa anual y, en su seno, el sector manufacturero un 4,5\%. Entre las actividades sustitutivas de importaciones, se destaca la rama de los minerales no metálicos, que es especialmente demandante de energía. Pero además, puede constatarse un incremento importante de importación de combustibles y un considerable aumento de la importación de bienes 


\section{CUADRO 10}

SECTOR INDUSTRIAL: CABALLOS DE FUERZA DE LOS MOTORES SEGÚN EL ENERGÉTICO UTILIZADO. MONTEVIDEO, 1908 Y 1936

\begin{tabular}{|l|c|c|c|c|}
\hline & \multicolumn{2}{|c|}{ Potencia instalada (1908) } & \multicolumn{2}{c|}{ Potencia instalada (1936) } \\
\hline & HP & $\%$ & HP & $\%$ \\
\hline Carbón & 16.750 & 73,5 & 9.049 & 10,0 \\
\hline Gas & 544 & 2,4 & & \\
\hline Petróleo & & & 7.651 & 8,5 \\
\hline Electricidad & 5.392 & 23,7 & 73.428 & 81,5 \\
\hline Hidráulica & 102 & 0,4 & & 100,0 \\
\hline Total & 22.788 & 100,0 & 90.128 & \\
\hline
\end{tabular}

Fuentes: DGE (1912) y Ministerio de Industrias y Trabajo (1939).

de capital con destino a la producción industrial, en particular hacia el final de la década de $1920^{30}$. Esta dinámica habría tenido en los derivados del petróleo un insumo fundamental.

\section{FACTORES EXPLICATIVOS DE LA TRANSICIÓN: PRECIOS, TECNOLOGÍA E INSTITUCIONES}

En el apartado anterior se realizó un análisis descriptivo sobre la evolución del consumo de carbón por parte de ciertos sectores intensivos en el uso de esta fuente de energía. A pesar de la visión fragmentaria de lo ocurrido en el sector eléctrico, con la producción de gas, con el combustible utilizado por los ferrocarriles y con la energía que movió a la industria, esta ofrece información importante para aproximarse al fenómeno del auge y ocaso en el consumo de carbón y al proceso de la transición hacia el petróleo.

La transición del carbón operó a lo largo de las cuatro décadas que se iniciaron en tiempos de la primera guerra mundial. Esta mirada sectorial permite identificar diferentes dinámicas de este fenómeno: por un lado, un proceso relativamente acelerado de sustitución en algunas actividades a partir de la primera guerra mundial, como lo evidencia el uso del carbón en el transporte ferroviario y en la industria; y, por otro, un proceso de sustitución «demorado» en el sector energético por el mantenimiento del carbón como insumo básico de la producción de gas y un retorno en los años treinta al carbón para generación de energía eléctrica.

\footnotetext{
${ }^{30}$ Cf. Bertino et al. (2005).
} 
Ahora bien, resta por explicar cuáles fueron los principales factores que impulsaron a las compañías ferroviarias, eléctricas, del gas y al sector industrial a realizar la sustitución del carbón. El estudio se centrará en tres aspectos: las alteraciones en los precios y fletes internacionales, las innovaciones tecnológicas y las cuestiones de orden institucional.

\subsection{Encarecimiento relativo del carbón}

El análisis de las series de precios del carbón y del petróleo que debió pagar Uruguay en la primera mitad del siglo XX se dificulta por la ausencia de estadísticas oficiales que manejen valores de mercado para las importaciones. Hasta 1941, la Dirección Nacional de Aduanas, organismo encargado del registro del comercio exterior, maneja precios de aforo para las mercaderías ingresadas a los efectos de estimar los impuestos que se deben pagar por las mismas. Esto obliga a trabajar a partir de precios internacionales, pero entonces surge el problema de cómo estimar el costo de los fletes para obtener un precio CIF Montevideo.

Dados los objetivos de este trabajo, en este apartado solo se pretende encontrar señales en el mercado internacional que pudieron contribuir a la toma de decisiones de los actores estratégicos. En tal sentido, la evolución de los precios relativos de carbón mineral y petróleo ofrece una aproximación.

En el Gráfico 6 se presenta el precio de una tonelada equivalente petróleo (TEP) en relación con el carbón mineral ${ }^{31}$. Desde 1900 , se constata una tendencia descendente del precio del petróleo en términos relativos al carbón mineral. El período que particularmente interesa para discutir la transición se inicia en torno a la primera guerra mundial. Como puede observarse, el precio promedio del petróleo alcanza casi tres veces el precio del carbón en la década de 1910, se reduce a dos veces y media en la de 1920 y sigue disminuyendo en las décadas sucesivas.

Si se tienen en cuenta los problemas de abastecimiento originados en la primera guerra mundial y la evolución de los precios relativos desde entonces, podría existir un incentivo para el cambio de fuente energética.

En cuanto a los fletes, existen indicios de cierta tendencia a favor de los costos de transporte del petróleo en relación con el carbón mineral. En primer lugar, durante los años veinte y treinta, Uruguay se abastecía de petróleo y derivados desde el continente americano (Estados Unidos, México, Perú, Ecuador, Venezuela), lo que «acorta las distancias» respecto a la provisión de carbón mineral, que continúa siendo desde el Reino Unido de

31 El coeficiente de conversión utilizado fue 1 TEP = 1,43 t de carbón mineral. Esta estimación se fundamenta en el poder calorífico inferior promedio entre la antracita y los carbones bituminosos, ya que las importaciones de carbón mineral de Uruguay provenían, en aproximadamente un 90\%, del Reino Unido y, según Mitchell (1985), ese carbón era steam coal, que podría definirse como «semiantracita». 


\section{GRÁFICO 6 \\ PRECIO RELATIVO DEL PETRÓLEO EN RELACIÓN CON EL DEL CARBÓN (TEP, SERIE ORIGINAL Y TENDENCIA). DÓLARES CORRIENTES, 1879-1950}

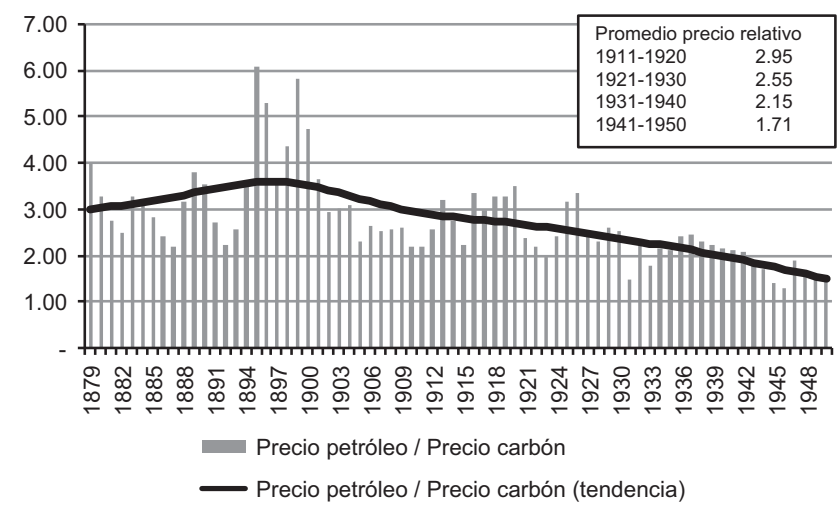

Fuentes: precio del carbón de Santa Fe Institute, en McNerney et al. (2011) y del petróleo de British Petroleum (2012).

Nota: la tendencia de la serie se estimó aplicando el filtro de Hodrick-Prescott.

manera excluyente. La menor distancia debería haber incidido en el precio de los fletes respectivos según Bertoni et al. (2009).

Según Nahum (2003, p. 325), en 1933 el carbón importado por Uruguay salía del Reino Unido con un precio FOB de 16,6 chelines por tonelada y pagaba un flete de 8,8 chelines por tonelada. Por su parte, la ANCAP estimaba el flete del crudo importado en un poco más de un tercio del precio FOB.

En un contexto de abaratamiento relativo del petróleo, los costos de los fletes no habrían operado en perjuicio de la transición al petróleo. Como ha sido señalado ${ }^{32}$ :

«Cuando el petróleo apareció como una alternativa económica y tecnológicamente viable en los años de entreguerras, Uruguay se encontró ante la situación de enfrentar fletes más favorables para el petróleo que para el carbón, lo que parece ser una buena justificación para emprender una temprana transición al petróleo.»

En relación con los precios domésticos, las memorias de Central Uruguay Railway Company aportan evidencia reveladora de la alteración de los costos energéticos que afrontaban las empresas en Uruguay. A partir de los reportes anuales, se puede extraer información sobre los cambios en los precios de la

32 En Bertoni et al. (2009). 
tonelada de carbón mineral que pagaba dicha compañía y se convierten en testimonio del encarecimiento de este energético ya en vísperas de la primera guerra mundial. Pero la situación se agravó. El costo de la tonelada de carbón en 1910-1911 era de 1,51 libras, subió casi al doble durante el conflicto y continuó incrementándose durante los años siguientes. En 1915-1916, el precio de la tonelada de carbón era de 2,9 libras; en 1918-1919, era de 6,5 libras; y, al año siguiente, de 5,3 libras. El encarecimiento del carbón, junto con las dificultades de abastecimiento, continuaron durante los años siguientes a la guerra, lo que derivó en la adopción de una nueva estrategia energética: el uso de locomotoras a petróleo (como se explicó en el apartado 5.3).

\subsection{Innovación tecnológica: ¿americanización de la tecnología?}

La adopción de nuevas formas de producir y la incorporación a la canasta de consumo de bienes nuevos, implicaron demandas energéticas asociadas a fuentes diferentes al carbón, como era el petróleo. Tal es el caso de los motores a combustión interna, la «dieselización» del ferrocarril y la electrificación de las pequeñas localidades del país. En este contexto, el transporte automotor merece atención especial. El automóvil, como vehículo de las familias, y las camionetas y camiones para el transporte de bienes aparecieron en escena y provocaron una demanda de derivados del petróleo.

Como se señala en Bertino et al. (2005), la innovación que revolucionó el sector transporte después de la primera guerra mundial fue la derivada de la combustión del petróleo, en clara correspondencia con la nueva hegemonía mundial de Estados Unidos, donde se concentraba la mayor parte de las empresas petroleras y de las fábricas de automotores y neumáticos.

El incremento en la importación de automóviles (equivalente al consumo interno, puesto que no existe producción doméstica de este bien) es fiel reflejo de la acelerada adopción de esta tecnología. Tomando las cifras de comercio exterior, en 1903 aparece un solo automóvil importado, en 1915 la cantidad era de 183, en 1920 ascendió a 4.142 unidades, y la acumulación entre 1915 y 1933 fue de 51.686 unidades importadas ${ }^{33}$.

Otro indicador de esta revolución de los transportes se observa en el incremento del transporte carretero de pasajeros y de carga; por ejemplo, medido a partir del crecimiento del valor agregado bruto. Este sector tuvo una dinámica sobresaliente, en especial durante los años veinte: el crecimiento promedio anual fue de un $16,1 \%$ entre 1921 y 1925 , y de un $19,3 \%$ entre 1926 y $1930^{34}$. La transformación en el transporte se produce, como ha sido señalado, en paralelo a una sustitución del carbón por derivados del petróleo en las locomotorasdel ferrocarril. Algunos autores han

\footnotetext{
33 Según datos de los anuarios estadísticos publicados en Nahum (2007).

34 Calculado a partir de cifras de Bertino y Tajam (1999).
} 
caracterizado este fenómeno como un cambio tecnológico asociado al agotamiento de la «tecnología británica» y a la emergencia de una «tecnología americana» ${ }^{35}$. En Uruguay, se habla de un proceso de dieselización del parque de locomotoras que culminó con la nacionalización del ferrocarril y la consolidación de la Administración de Ferrocarriles del Estado en la segunda posguerra.

Como se presentó en el apartado 5.1, Uruguay vivió durante la primera mitad del siglo XX un importante proceso de electrificación. Dado que las líneas de trasmisión fueron extendiéndose lentamente por el territorio, la solución técnica fue la generación distribuida. Para brindar el acceso a la electricidad a pequeñas localidades se instalaron generadores a fueloil o a diésel oil. Antes de 1912, fecha en que se creó la empresa UEE con el monopolio sobre la generación, trasmisión y distribución de la energía eléctrica a escala nacional, había 13 usinas a carbón en todo el país. Entre 1912 y 1935 se crearon 30 usinas de generación, todas ellas consumiendo fueloil o diésel oil, dado que el tamaño de las mismas se correspondía con este tipo de tecnología. A esto debe sumarse la transformación progresiva de las 13 primeras usinas para consumir derivados del petróleo como energético ${ }^{36}$.

Finalmente, cabe señalar que el incentivo para adoptar derivados del petróleo para la generación se fundaba en una razón de eficiencia. Oxman (1961, p. 21) señala, a partir de información de UTE, que los rendimientos técnicos del proceso generador habrían experimentado importantes mejoras con la incorporación de los derivados del petróleo. En 1948, cada kw/h generado requería un consumo de $0,58 \mathrm{~kg}$ de petróleo, mientras que en 1960 este coeficiente había caído a $0,36 \mathrm{~kg}$.

La incorporación de la hidroelectricidad a la matriz energética a partir de 1945-1948 completó un escenario de cambio tecnológico que marginaba al carbón como combustible para generación.

\subsection{Aspectos institucionales: enfrentamiento al «empresismo británico»}

Entre los factores explicativos de la transición del carbón al petróleo, no puede olvidarse la variable político-institucional. Los elencos «batllistas» ${ }^{37}$ en el poder en las primeras tres décadas del siglo XX y, particularmente, durante el segundo Gobierno de José Batlle y Ordóñez (1911-1915), desarrollaron una política deliberada de enfrentamiento al «empresismo británico».

\footnotetext{
35 Por ejemplo, Guajardo (2005).

36 Véase Bertoni (2002).

37 Se define como tal a la reformista del partido colorado, liderada por don José Batlle y Ordóñez. La política uruguaya durante las tres primeras décadas del siglo XX estuvo fuertemente impregnada de esta ideología.
} 
La creación de empresas públicas proveedoras de servicios públicos para evitar monopolios privados se complementó con obras de infraestructura que compitieran con el capital británico dueño de gran parte del transporte de carga y pasajeros. Como se señala en Bertino et al. (2005), en el discurso batllista, el desarrollo de las capacidades estatales se asoció con la defensa del interés nacional frente al capital extranjero y, en esta línea, la política de nacionalizaciones y estatizaciones hizo del Estado un agente relevante para las dimensiones de la estructura económica del país. En términos generales, el avance del Estado se habría llevado a cabo a costa del capital extranjero, mayoritariamente británico.

El impulso a la expansión de la red carretera nacional simultáneamente con los ferrocarriles del Estado debe considerarse parte de esta impronta «antibritánica». Es en este contexto, en el que deben ubicarse los planes de obras públicas que contemplaban el trazado de una red de carreteras, muchas de ellas paralelas a las vías de Central Uruguay Railway Company. Los planes de 1905 y 1909, así como la expansión carretera en los años veinte, deben analizarse desde esta perspectiva. El resultado fue la emergencia de la infraestructura necesaria para que el transporte automotor, una nueva tecnología intensiva en el uso de derivados del petróleo, compitiera con los ferrocarriles británicos.

\section{CONCLUSIONES}

El auge y el ocaso del carbón mineral son manifestaciones del proceso de modernización energética. La estimación histórica de una serie en Uruguay, ajustando el problema estadístico originado por el abastecimiento de carbón a los buques, permite analizar el consumo de carbón y, complementariamente, la dinámica de la transición fósil.

La «era del carbón» en Uruguay, en lo que respecta a su aporte como energético asociado al crecimiento económico, debería ubicarse en las primeras décadas del siglo XX. La energía necesaria para los procesos de valorización sería aportada crecientemente después de la primera guerra mundial por otros vectores como el petróleo.

La demanda efectiva de cuatro grandes consumidores, las usinas eléctricas, la producción de gas, los ferrocarriles y la industria, que hacia 1909-1911 utilizaban el $84 \%$ del carbón, contribuye a explicar el comportamiento del carbón mineral. La evidencia manejada permite afirmar que la transición al petróleo se operó a lo largo de cuatro décadas, que se inician alrededor de la primera guerra mundial.

No obstante, el fenómeno es el resultado de tres trayectorias diferentes: la sustitución del carbón por otro energético (caso del ferrocarril y la actividad industrial), el surgimiento de nuevas actividades intensivas en el uso de otra fuente de energía (el transporte automotor) y el parcial retorno al carbón en 
los años treinta, como es el caso de la generación de electricidad. Como resultado, la competencia entre el carbón y el petróleo solo se produjo en algunos ámbitos, lo cual explica que el proceso de transición no se haya completado hasta después de la segunda guerra mundial. A la luz de estos resultados, es posible afirmar que el ocaso del carbón aparecería, como antes su auge, como una manifestación del proceso de modernización energética.

Esta dinámica confirma el modelo uruguayo, de retrocesos y recuperación, identificado por otros estudios comparativos a escala regional. La nueva serie construida permite corregir los niveles de consumo de carbón per cápita manejados por esos trabajos y altera la posición de Uruguay en el contexto regional durante el primer cuarto del siglo XX. En este sentido, si bien se mantiene entre los cuatro principales consumidores de carbón, se coloca detrás de Argentina, Chile y Cuba, lo que refleja una realidad más acorde con la economía uruguaya de entonces.

La modernización económica, el incipiente desarrollo industrial y el acelerado proceso urbanístico que vivió Uruguay durante las primeras décadas del siglo XX incidieron en el ritmo de la transición fósil. Pero además, con estos fenómenos interactuaron los problemas de abastecimiento emergentes durante la —llamada por Hobsbawm- «era de las catástrofes», la alteración en los precios relativos, la dinámica del cambio tecnológico y factores de orden institucional.

Un encarecimiento del precio del carbón respecto al petróleo actuó como incentivo para adoptar una tecnología nueva y más eficiente (el motor de combustión interna) y este proceso encontró un marco institucional favorable a partir de las acciones gubernamentales hostiles hacia el «empresismo inglés».

\section{FUENTES}

Administración de los Ferrocarriles y Tranvías del Estado: Memorias (varios años).

Administración Nacional de Combustibles, Alcohol y Portland (ANCAP): Boletín Estadístico (varios años).

British Petroleum (2012): Statistical Review of Energy World Report.

Central Uruguay Railway Company of Montevideo (CUR): Report of the directors to the shareholders with statement of the revenue and capital account. For the years ended June 30 ${ }^{\text {th }}$ (1901-1940).

Dirección General de Estadística (DGE): Anuarios Estadísticos (varios años). Montevideo.

Dirección General de Estadística (DGE): Síntesis Estadística de la República Oriental del Uruguay. Montevideo (varios años).

Dirección General de Estadística (DGE) (1912): “Censo General 1908», Anuario Estadístico 1909-1910. Montevideo. 
Dirección de Estadística General (DEG) (1877): Comercio, navegación y hacienda pública. Estadística del Comercio Exterior correspondiente a los años 1874 y 1875 Cuaderno núm. 8. Montevideo: Imprenta de El Siglo.

Dirección Nacional de Energía (DNE): Balance Energético Nacional (varios años). En: <http://www.dne.gub.uy/>.

Ministerio de Industrias y Trabajo (1939): Censo Industrial de 1936. Montevideo: Dirección de Estadística Económica.

Oficina de Estadística Comercial (1916): Comercio Exterior de la República Oriental del Uruguay. Comercio Especial, años 1915, 1916. Uruguay.

Registro Nacional de Leyes y Decretos (RNLD): Año 1916. Montevideo: Imprenta Nacional.

Statistical Office of the Customs and Excise Department: Annual Statement of the United Kingdom with Foreign Countries and British Possessions. Londres, (varios años).

\section{BIBLIOGRAFÍA}

Acevedo, E. (1933): Anales de la Universidad, t. III. Montevideo: Casa A. Barreiro y Ramos.

Barrán, J. P. y Nahum, B. (1978): Historia Rural del Uruguay Moderno, t. VII: Agricultura, Crédito y Transporte bajo Batlle (1904-1914). Montevideo: Ediciones de la Banda Oriental.

Bertino, M., Bertoni, R., Tajam, H. y Yaffé, J. (2005): Historia Económica del Uruguay, t. III: La economía del batllismo y de los años veinte. Montevideo: Editorial Fin de Siglo.

Bertino, M. y TaJam, H. (1999): El PBI del Uruguay 1900-1955. Montevideo: Facultad de Ciencias Económicas y de Administración y Comisión Sectorial de Investigación Científica, Universidad de la República.

Bértola, L., Calicchio, L., Camou, M. y Rivero, L. (1998): El PBI uruguayo 1870-1936 y otras estimaciones. Montevideo: Facultad de Ciencias Sociales, Universidad de la República.

Bertoni, R. (2002): «Economía y cambio técnico. Adopción y difusión de la energía eléctrica de Uruguay. 1880-1980». Mimeo, Montevideo: Facultad de Ciencias Sociales, Universidad de la República.

BERTONI, R. (2011): Energía y desarrollo. La restricción energética en Uruguay como problema (1882-2000). Montevideo: Universidad de la República.

Bertoni, R., Echinope, V., Gaudioso, R., Laureiro, R., Loustaunau, M. y Taks, J. (2011): La matriz energética: una construcción social. Montevideo: Universidad de la República.

Bertoni, R. y Román, C. (2006): «Estimación y Análisis de la Economic Kuznets Curve en Uruguay» [comunicación]. III Simposio Latinoamericano y Caribeño de Historia Ambiental-III Encuentro Español de Historia Ambiental. Carmona. 
Bertoni, R. y Román, C. (2008): «La transición energética en Uruguay (1882-2000)» en M. Rubio y R. Bertoni (comp.), Energía y Desarrollo en el largo siglo XX. Uruguay en el marco Latinoamericano. Montevideo: Universitat Pompeu Fabra-Universidad de la República, pp. 153-178.

Bertoni, R., Román, C. y Rubio, M. (2009): «El desarrollo energético de España y Uruguay en perspectiva comparada: 1860-2000». Revista de Historia Industrial 41, XVIII (3), pp. 161-194.

Bonino, N., Román, C. y Willebald, H. (2012): «PIB y estructura productiva en Uruguay (1870-2011): Revisión de series históricas y discusión metodológica»[documento de trabajo, 05/12]. Montevideo: Facultad de Ciencias Económicas y de Administración, Universidad de la República. Diagnóstico y Plan de Energía $1965-1974$ (1965). Montevideo: Comisión de Inversiones y Desarrollo Económico (CIDE).

DíAz, G. (2011): «La financiación pública del ferrocarril uruguayo: 18691913» [comunicación], $5^{\text {as }}$ Jornadas de Historia Económica, Asociación Uruguaya de Historia Económica, Montevideo.

Folchi, M. y RuBio, M. (2006): «El consumo de energía fósil y la especificidad de la transición energética en América Latina, 1900-1930»[comunicación]. XIV International Economic History Congress, Helsinki.

Folchi, M. y RuBio, M. (2008): «El consumo aparente de energía fósil en los países latinoamericanos en 1925: una propuesta metodológica a partir de las estadísticas de comercio exterior», en M. Rubio y R. Bertoni (comp.), Energía y Desarrollo en el largo siglo XX. Uruguay en el marco Latinoamericano. Montevideo: Universitat Pompeu Fabra-Universidad de la República, pp. 19-72.

Gales, B., Kander, A., Malanima, P. y Rubio, M. (2007): «North versus South: Energy Transition and Energy Intensity in Europe over 200 years». European Review of Economic History 11, pp. 219-53.

GuAJARDO, G. (2005): «La tecnología de los Estados Unidos y la "americanización” de los ferrocarriles estatales de México y Chile, c. 1880-1950». Transportes, Servicios y Telecomunicaciones 9, pp. 110-129.

JАсов, R. (1979): Inversiones Extranjeras y Petróleo. Montevideo: Fondo de Cultura Universitaria.

Labraga, A., NúÑez, M., Rodríguez, A. y Ruiz, E. (1991): Energía y Política en el Uruguay del siglo XX, t. I: Del carbón al petróleo: en mano de los trusts (1900-1930). Montevideo: Ediciones Banda Oriental.

MaEso, C. M. (1910): El Uruguay a través de un siglo. Montevideo: Imprenta La Moderna.

Mcnerney, J., Dyne, J. y TranciK, J. (2011): «Historical costs of coalfired electricity and implications for the future». Energy Policy 36 (6), pp. 3.042-3.054.

MÉndez Galain, R. (2008): Área Energía. Informe final de la consultoría sobre energía en el marco del PENCTI. Montevideo: Agencia Nacional de Investigación e Innovación. 
Mitchell, B. R. (1985): British Historical Statistics. Cambridge: Cambridge University Press.

NaHum, B. (2003): Uruguay-Inglaterra. Sus relaciones financieras hasta mediados del siglo XX. Montevideo: Banda Oriental.

Nahum, B. (Coord.) (2007): Estadísticas históricas del Uruguay 1900-1950. Montevideo: Universidad de la República.

Oxman, R. (1961): «Energía. Producción y Consumo. Instituto de Teoría y Política Económica». Cuaderno 23. Montevideo: Facultad de Ciencias Económicas y de Administración, Universidad de la República.

REYNOLDS, D. (1996): «Energy Grades and Economic Growth». The Journal of Energy and Development 19, pp. 245-264.

Rubio, M. y Folchi, M. (2012): «Will small energy consumers be faster in transition? Evidence from the early shift from coal to oil in Latin America». Energy Policy, Elsevier 50 (C), pp. 50-61.

Rubio, M., Yáñez, C., Folchi, M. y CARReras, A. (2010): «Energy as an indicator of modernization in Latin America, 1890-1925». Economic History Review 63 (3), pp. 769-804.

Stern, D. y Cleveland, C. (2004): «Energy and Economic Growth» [cuaderno de trabajo]. Working Papers in Economics. Rensselaer Polytechnic Institute.

Stevens, P. (ed.) (2000): «The Economics of Energy». The International Library of Critical Writings in Economics 119. Edward Elgar Publishing Limited, vol. I.

Vaillant, A. (1873): Cuaderno de Estadísticas [informe presentado a la Exposición Internacional de Viena]. Montevideo.

Yañez, C., Rubio, M. y Carreras, A. (2008): «Modernización económica en América Latina y el Caribe entre 1890 y 1925: una mirada desde el consumo de energía», en M. Rubio y R. Bertoni (comp.), Energía y desarrollo en el largo siglo XX. Uruguay en el marco latinoamericano. Montevideo: Universitat Pompeu Fabra-Universidad de la República, pp. 91-120. 


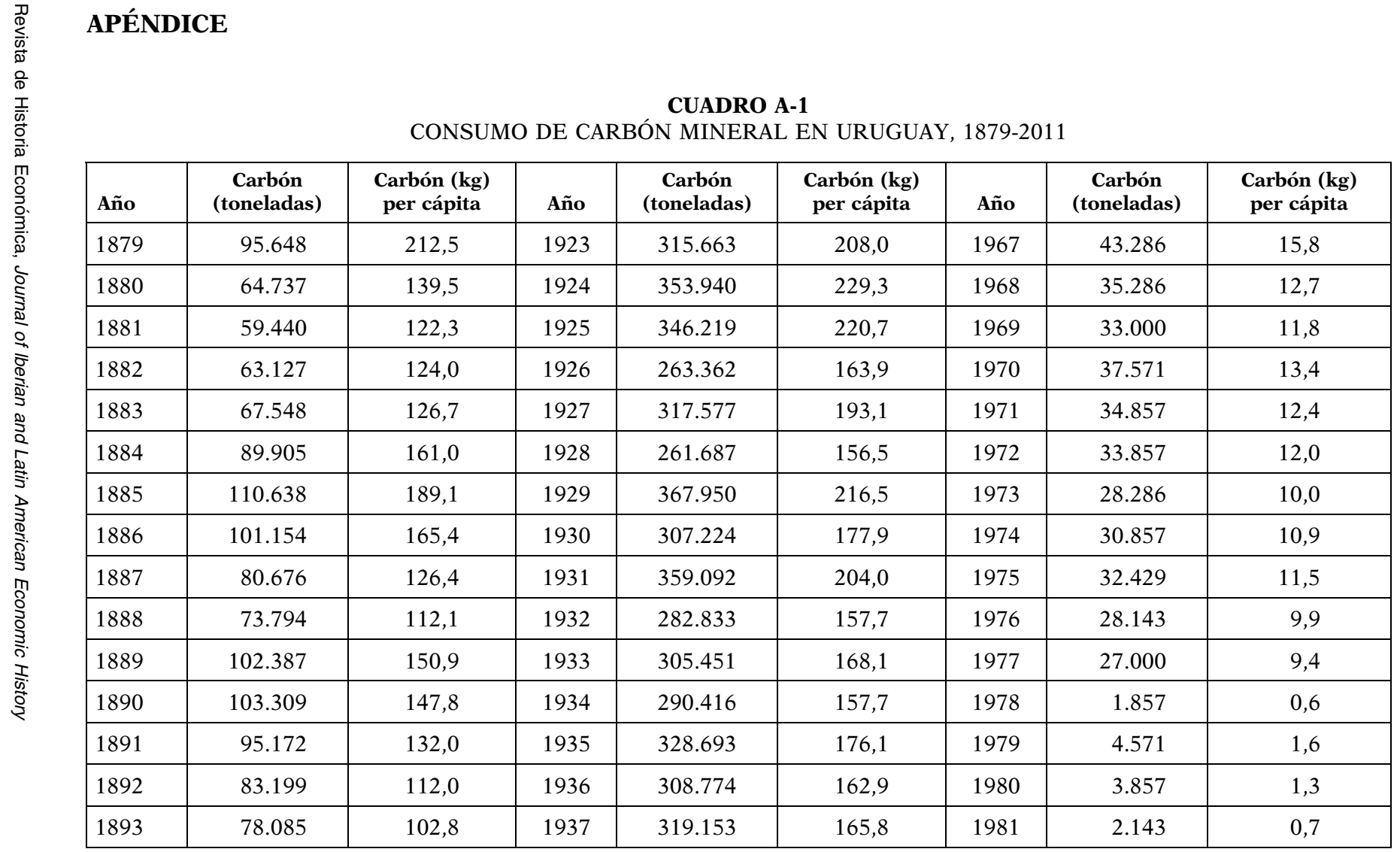


CUADRO A-1 (Cont.)

\begin{tabular}{|c|c|c|c|c|c|c|c|c|}
\hline Año & $\begin{array}{c}\text { Carbón } \\
\text { (toneladas) }\end{array}$ & $\begin{array}{c}\text { Carbón (kg) } \\
\text { per cápita }\end{array}$ & Año & $\begin{array}{c}\text { Carbón } \\
\text { (toneladas) }\end{array}$ & $\begin{array}{l}\text { Carbón }(\mathbf{k g}) \\
\text { per cápita }\end{array}$ & Año & $\begin{array}{c}\text { Carbón } \\
\text { (toneladas) }\end{array}$ & $\begin{array}{c}\text { Carbón }(\mathbf{k g}) \\
\text { per cápita }\end{array}$ \\
\hline 1894 & 140.247 & 180,8 & 1938 & 288.596 & 148,3 & 1982 & 857 & 0,3 \\
\hline 1895 & 124.026 & 156,6 & 1939 & 336.129 & 170,9 & 1983 & 143 & 0,0 \\
\hline 1896 & 111.858 & 137,0 & 1940 & 380.267 & 191,3 & 1984 & 286 & 0,1 \\
\hline 1897 & 79.311 & 94,3 & 1941 & 302.177 & 150,0 & 1985 & 429 & 0,1 \\
\hline 1898 & 102.114 & 118,8 & 1942 & 213.900 & 104,8 & 1986 & 429 & 0,1 \\
\hline 1899 & 142.250 & 161,9 & 1943 & 327.641 & 159,0 & 1987 & 429 & 0,1 \\
\hline 1900 & 115.456 & 128,7 & 1944 & 269.922 & 129,7 & 1988 & 429 & 0,1 \\
\hline 1901 & 121.726 & 131,6 & 1945 & 331.036 & 157,6 & 1989 & 429 & 0,1 \\
\hline 1902 & 127.281 & 133,7 & 1946 & 166.367 & 78,0 & 1990 & 571 & 0,2 \\
\hline 1903 & 139.600 & 143,5 & 1947 & 125.624 & 58,0 & 1991 & 429 & 0,1 \\
\hline 1904 & 152.623 & 153,6 & 1948 & 139.205 & 63,6 & 1992 & 143 & 0,0 \\
\hline 1905 & 147.573 & 145,5 & 1949 & 139.205 & 62,9 & 1993 & 143 & 0,0 \\
\hline 1906 & 186.080 & 177,1 & 1950 & 147.693 & 66,1 & 1994 & 143 & 0,0 \\
\hline 1907 & 202.995 & 186,7 & 1951 & 162.972 & 71,8 & 1995 & 429 & 0,1 \\
\hline 1908 & 274.679 & 246,5 & 1952 & 103.555 & 44,9 & 1996 & 714 & 0,2 \\
\hline 1909 & 227.417 & 199,2 & 1953 & 106.950 & 45,9 & 1997 & 571 & 0,2 \\
\hline 1910 & 237.784 & 203,4 & 1954 & 108.648 & 46,1 & 1998 & 571 & 0,2 \\
\hline 1911 & 284.725 & 236,9 & 1955 & 129.019 & 54,1 & 1999 & 857 & 0,3 \\
\hline
\end{tabular}


CUADRO A-1 (Cont.)

\begin{tabular}{|c|c|c|c|c|c|c|c|c|}
\hline 1912 & 338.229 & 273,9 & 1956 & 110.345 & 45,6 & 2000 & 571 & 0,2 \\
\hline 1913 & 328.493 & 260,9 & 1957 & 103.555 & 42,1 & 2001 & 857 & 0,3 \\
\hline 1914 & 375.791 & 292,9 & 1958 & 110.345 & 44,4 & 2002 & 1.286 & 0,4 \\
\hline 1915 & 253.435 & 193,9 & 1959 & 56.022 & 22,3 & 2003 & 571 & 0,2 \\
\hline 1916 & 217.689 & 163,1 & 1960 & 98.462 & 38,8 & 2004 & 1.143 & 0,3 \\
\hline 1917 & 158.121 & 116,1 & 1961 & 69.955 & 27,2 & 2005 & 1.286 & 0,4 \\
\hline 1918 & 273.200 & 197,7 & 1962 & 61.378 & 23,5 & 2006 & 1.714 & 0,5 \\
\hline 1919 & 305.498 & 217,9 & 1963 & 66.809 & 25,4 & 2007 & 2.143 & 0,6 \\
\hline 1920 & 292.612 & 205,8 & 1964 & 46.381 & 17,4 & 2008 & 1.857 & 0,6 \\
\hline 1921 & 175.318 & 120,3 & 1965 & 45.143 & 16,8 & 2009 & 2.286 & 0,7 \\
\hline 1922 & 312.085 & 209,2 & 1966 & 38.000 & 14,0 & 2010 & 3.857 & 1,1 \\
\hline & & & & & & 2011 & 2.143 & 0,6 \\
\hline
\end{tabular}

Fuentes: elaboración propia; consúltese el apartado 3 con los detalles. 